\title{
Bone regeneration in the presence of a synthetic hydroxyapatite/silica oxide-based and a xenogenic hydroxyapatite-based bone substitute materia
}

Kruse, A ; Jung, R E ; Nicholls, F ; Zwahlen, R A ; Hämmerle, C H F ; Weber, Franz E

\begin{abstract}
Objectives: A comparison of synthetic hydroxyapatite/silica oxide, xenogenic hydroxyapatite-based bone substitute materials with empty control sites in terms of bone regeneration enhancement in a rabbit calvarial four non-critical-sized defect model. Methods: In each of six rabbits, four bicortical calvarial bone defects were generated. The following four treatment modalities were randomly allocated: (1) empty control site, (2) synthetic hydroxyapatite/silica oxide-based $(\mathrm{HA} / \mathrm{SiO})$ test granules, (3) xenogenic hydroxyapatite -based granules, (4) synthetic hydroxyapatite/silica oxide -based $(\mathrm{HA} / \mathrm{SiO})$ test two granules. The results of the latter granules have not been reported due to their size being three times bigger than the other two granule types. After 4 weeks, the animals were sacrificed and un-decalcified sections were obtained for histological analyses. For statistical analysis, the Kruskal-Wallis test was applied $(\mathrm{P}<0.05)$. Results: Histomorphometric analysis showed an average area fraction of newly formed bone of $12.32 \pm 10.36 \%$ for the empty control, $17.47 \pm 6.42 \%$ for the xenogenic hydroxyapatite -based granules group, and $21.2 \pm 5.32 \%$ for the group treated with synthetic hydroxyapatite/silica oxide -based granules. Based on the middle section, newly formed bone bridged the defect to $38.33 \pm 37.55 \%$ in the empty control group, $54.33 \pm 22.12 \%$ in the xenogenic hydroxyapatite -based granules group, and to $79 \pm 13.31 \%$ in the synthetic hydroxyapatite/silica oxide -based granules group. The bone-to-bone substitute contact was $46.38 \pm 18.98 \%$ for the xenogenic and $59.86 \pm 14.92 \%$ for the synthetic hydroxyapatite/silica oxide-based granules group. No significant difference in terms of bone formation and defect bridging could be detected between the two bone substitute materials or the empty defect. Conclusion: There is evidence that the synthetic hydroxyapatite/silica oxide granules provide comparable results with a standard xenogenic bovine mineral in terms of bone formation and defect bridging in non-critical size defects. To cite this article: Kruse A, Jung RE, Nicholls F, Zwahlen RA, Hämmerle CHF, Weber FE. Bone regeneration in the presence of a synthetic hydroxyapatite/silica oxide -based and a xenogenic hydroxyapatite -based bone substitute material.
\end{abstract}

DOI: https://doi.org/10.1111/j.1600-0501.2010.02039.x

Posted at the Zurich Open Repository and Archive, University of Zurich

ZORA URL: https://doi.org/10.5167/uzh-40370

Journal Article

Accepted Version

Originally published at:

Kruse, A; Jung, R E; Nicholls, F; Zwahlen, R A; Hämmerle, C H F; Weber, Franz E (2011). Bone regeneration in the presence of a synthetic hydroxyapatite/silica oxide-based and a xenogenic hydroxyapatite-based bone substitute materia. Clinical Oral Implants Research, 22(5):506-511.

DOI: https://doi.org/10.1111/j.1600-0501.2010.02039.x 


\title{
Bone regeneration in the presence of a synthetic hydroxyapatite/silica oxide based and a xenogenic hydroxyapatite based bone substitute material
}

\author{
Kruse $A^{1}$, Jung $R E^{2}$, Nicholls $F^{3}$, Zwahlen $R^{1}$, Hämmerle $\mathrm{CHF}^{2}$, \\ Weber $\mathrm{FE}^{1 *}$ \\ ${ }^{1}$ University Hospital Zurich; Dept. of Cranio-Maxillofacial Surgery, Oral Biotechnology \& \\ Bioengineering; Frauenklinikstrasse 24, 8091 Zürich; Switzerland \\ ${ }^{2}$ Department of Fixed and Removable Prothodontics and Dental Material Science, Dental \\ School, University of Zurich, Switzerland \\ ${ }^{3}$ University Hospital Zurich; ZKF; Zurich; Switzerland
}

* Corresponding author: FE Weber, University Hospital; Dept. of Cranio-Maxillofacial Surgery, Oral Biotechnology \& Bioengineering; Frauenklinikstrasse 24, 8091 Zürich; Switzerland Tel: +41 44255 5055, Fax: +41 442554179

e-mail: franz.weber@zzmk.uzh.ch

Key words: bone substitute material, nano-crystalline hydroxyapatite, bone regeneration 


\section{Abstract:}

Objectives: Comparison of synthetic hydroxyapatite/silica oxide, xenogenic hydroxyapatite based bone substitute materials with empty control sites in terms of bone regeneration enhancement in a rabbit calvarial 4 non-critical sized defect model.

Methods: In each of six rabbits, four bicortical calvarial bone defects were generated. The following four treatment modalities were randomly allocated: (1) empty control site, (2) synthetic hydroxyapatite/silica oxide based (HA/SiO) test granules, (3) xenogenic hydroxyapatite based granules, (4) synthetic hydroxyapatite/silica oxide based $(\mathrm{HA} / \mathrm{SiO})$ test 2 granules. The results of the latter granules have not been reported due to their size being 3 times bigger than the other two granule types. After four weeks, the animals were sacrificed and un-decalcified sections were obtained for histological analyses.

For statistical analysis the Kruskan-Wallis test was applied $(p<0.05)$.

Results: Histomorphometric analysis showed an average area fraction of newly formed bone of $12.32 \pm 10.36 \%$ for the empty control, $17.47 \pm 6.42 \%$ for the xenogenic hydroxyapatite based granules group, and $21.20 \pm 5.32 \%$ for the group treated with synthetic hydroxyapatite/silica oxide based granules. Based on the middle section, newly formed bone bridged the defect to $38.33 \pm 37.55 \%$ in the empty control group, $54.33 \pm 22.12 \%$ in the xenogenic hydroxyapatite based granules group, and to $79.00 \pm 13.31 \%$ in the synthetic hydroxyapatite/silica oxide based granules group. The bone to bone substitute contact was $46.38 \pm 18.98 \%$ for the xenogenic and $59.86 \pm 14.92 \%$ for the synthetic hydroxyapatite/silica oxide based granules group.

No significant difference in terms of bone formation and defect bridging could be detected between the two bone substitute materials or the empty defect.

Conclusion: There is evidence that the synthetic hydroxyapatite/silica oxide granules provide comparable results to a standard xenogenic bovine mineral in terms of bone formation and defect bridging in non critical size defects.

The substitution of autologous bone with synthetic materials to treat bone defects represents still a challenge. Hydrated calcium phosphates, as hydroxyapatite, are often used to develop synthetic bone substitutes due to their crystallographic structures similar to bone (Hing et al. 2006). For extended bone defects autologous 
bone is still the gold standard since hydroxyapatite based scaffolds need additions like stem cells (Cancedda et al. 2007) and/or growth factors (Warnke et al. 2006) to compete with them. For smaller defects, however, hydroxyapatite based scaffolds improved by the addition of inorganic substances like silicon or by the application of more sophisticated handling procedures omitting sintering yielding in a reduced osteoconductivity (Henkel et al. 2006) might also serve the purpose.

In 1970 Carlisle (Carlisle 1970) found out that deficiency in silicon lead to abnormal bone formation. Based on several other studies confirming this initial findings (Schwarz \& Milne 1972, Seaborn \& Nielsen 2002), silicon has become an important research topic in bone metabolism. Silicon is a major element in bioactive glass and contributes to its enhanced bioactivity in vitro (Gao et al. 2001, Gough et al. 2004) with significant up-regulation of osteoblast proliferation and gene expression when exposed to ionic dissolution products of bioactive glasses (Gao 2001, Hing et al. 2006, Xynos, et al. 2001).

In 2000, mimicking the postmenopausal state, Rico and co-workers (Rico et al. 2000) detected in ovariectomized rats, that very high level of dietary silicon may abolish bone mineral loss by increasing bone mineral content. A similar finding was stated in 2004 by Jugdaohsingh and co-workers (Jugdaohsingh et al. 2004) which suggested in their Framingham Offspring Cohort study that higher dietary silicon intake in men and younger women may have salutary effects on skeletal bone health, especially cortical bone health.

In the course of the development of synthetic bone substitution materials many researchers up to date have demonstrated in preclinical tests the benefits to early bone ingrowth and repair through incorporation of silicon into porous HA (Hing et al. 2006, Patel et al. 2005, Seaborn \& Nielsen 2002) or into calcium silicate ceramics (Xu et al. 2008). Others confirmed the influence of silicon on cell proliferation ability 
when compared to phase pure HA (Xu \& Khor 2007) in vitro. In a recent paper Huang and co-workers (Huang et al. 2008) showed that internalization of mesoporous silica nanoparticles induced a significant but transient osteogenic signal in human mesenchymal stem cells.

During their synthesis process, most bone substitutes are sintered resulting in more compact and less porous materials, where osteoconductivity might be reduced (Gerike et al. 2006). The present test material is a non-sintered nano-crystalline hydroxyapatite embedded in a highly porous silica gel matrix (HA/SiO). In order to guarantee both high osteoinductive property and biodegradability, the granules are loosely packed and present porosity between $60-80 \%$ (Werner et al. 2002). The gold standard bone substitute material is a deproteinized bovine bone mineral (DBBM), consisting of a mineral osseous matrix where the organic components have been removed by pyrolysis (Spector 1994), a procedure which also sinters the material.

Clinical outcomes of diverse procedures using DBBM are very well documented (Esposito et al. 2006, McAllister \& Haghighat 2007). Randomized clinical trials with the synthetic non-sintered $\mathrm{HA} / \mathrm{SiO}$ bone substitute material are not available yet but several studies have been published recently. An immunohistochemical study on biopsies from human jaws treated with the synthetic non-sintered $\mathrm{HA} / \mathrm{SiO}$ bone substitute material indicates that this material has osteoconductive and biomimetic properties and is integrated into the host's physiological bone turnover as early as 3.5 month postoperatively (Götz et al. 2008). A 3-year clinical and radiographic case study on 13 patients showed successful outcome of implants placed in conjunction with maxillary sinus floor augmentation using this synthetic hydroxyapatite/silica oxide based material (Heinemann et al. 2009). Another preliminary histological study with the same material shows sufficient bone formation in specimens harvested 6 months after sinus lifts were performed in severely resorbed maxillae (Canullo \& 
Dellavia 2009). In essence all the results published so far look promising but more information in particular comparing this material to the gold standard material are needed for the formulation of application specific recommendations for the practitioner.

The aim of this study was to compare bone regeneration in non critical size calvarial defects of rabbits treated with the gold standard DBBM, the non-sintered $\mathrm{HA} / \mathrm{SiO}$ or left untreated to directly compare the performance between the gold standard bone substitute and the newly developed material in vivo.

\section{Material and methods}

\section{Bone substitute materials}

Bone substitute materials of comparable size were used. The synthetic hydroxyapatite/silica oxide based granules are produced by Artoss (Rostock, Germany) and distributed as Nanobone® granules of $0.25-1 \mathrm{~mm}$ in diameter. NanoBone ${ }^{\circledR}$ is a fully synthetic bone graft substitute in granulate form. It consists of nanocrystalline hydroxyapatite (76 weight per cent) and silica (24 weight per cent). This bioceramic is produced using a modified technique at $200^{\circ} \mathrm{C}$. Material porosity exceeds $80 \%$, with pore sizes ranging from some nanometers to some 100 microns (Dietze et al. 2006). Xenogenic hydroxyapatite particles are produced by Geistlich Biomaterials (Wolhusen, Switzerland) and distributed as BioOss $\AA$ granules of $0.25-1$ $\mathrm{mm}$ in diameter. This natural product is deproteinized and sintered at $1100{ }^{\circ} \mathrm{C}$. Material porosity is between 70 and $75 \%$, with pore sizes from several nanometers to $1500 \mu \mathrm{m}$ (Benke et al. 2001, Peetz 1997). 


\section{Animal model}

Rabbits were sedated with $80 \mathrm{mg} / \mathrm{kg}$ Ketamin (Narketan® 10 ad us. vet., Injektionslösung, Ketamin 100mg/ml, Vetoquinol AG Ittigen, Bern Schweiz and Xylazin $2 \mathrm{mg} / \mathrm{kg}$ s.c (Rompun® $2 \%$ ad us. vet., Injektionslösung, Bayer Health Care Distribution Provet AG, Lyssach Schweiz.(Xylazinum 20mg $(\mathrm{ml})$. Inhalation with Isofluran was mainainted at $2 \%-2.5 \%$ (Attane, Isoflurane ad us vet. MINRAD INC, Buffalo, NY, USA, Distribution, Provet AG, Lyssach Schweiz). The flow rate for oxygen was $0.3 \mathrm{l} / \mathrm{min}$ and for $\mathrm{NO}_{2} 0.2 \mathrm{l} / \mathrm{min}$.

The surgical area was clipped and prepared with iodine for aseptic surgery. A linear incision was made from the nasal bone to the midsagittal crest. After the deflection of the soft tissues, a subperiosteal dissection of the operation site was performed (occipital, frontal, and parietal bones). Four $6 \mathrm{~mm}$ craniotomy defects were created (2 in the parietal and 2 in the frontal bone) with a $6 \mathrm{~mm}$ trephine bur using a dental hand piece (Jung, et al. 2005). The surgical area was rinsed with saline to remove bone debris. To avoid any dural perforation, the defects marked half way through the bone by the trephine bur were finalized by a round bur creating a $6 \mathrm{~mm}$ defect. The use of a round bur preserves the dura mater, which is strong enough to prevent a prolapse of brain tissue into $6 \mathrm{~mm}$ defects in the rabbit calvarium. In each animal, one untreated defect was compared to one defect treated with BioOss, and one treated with Nanobone ${ }^{\circledR}$. The forth defect was filled with another bone substitute of nonsintered nanocrystalline hydroxyapatite which was not included in this study report, since the size of these particles was much bigger than that of the other 2 bone substitutes (Fig 1). Prior to application both materials were wetted by a physiological saline solution to improve their ease of handling. Dependent on the thickness of the calvarial bone $0.075-0.10 \mathrm{~g}$ of bone substitute were placed in the defect so that the entire defect was filled and contoured like the original calvarial bone. After placement 
of the materials, the soft tissues were closed with sutures. Analgesia was provided with a Transdermal patch (Durogesic ${ }^{\circledR}$ Matrix JANSSEN-CILAG AG, Baar Switzerland: Durogesic Matrix $25 \mu \mathrm{g} / \mathrm{h}: 4.2 \mathrm{mg}$ Fentanyl per patch $10.5 \mathrm{~cm}^{2} ; 72$ hours). At 4 weeks the rabbits were sedated with Ketamin/Xylazin s.c, euthanized by an injection of Pentobarbital $120 \mathrm{mg} / \mathrm{kg}$ i.v. or i.cardial (Esconarkon ad us vet. Pentobarbitalum natricum 200mg; Streuli Pharma SA Uznach, Switzerland), and the calvarial bones were excised.

\section{Radiographical and histological analyses}

Specimens were $\mathrm{x}$-rayed using a dental radiographical unit with ultra speed dental films (Eastman Kodak Company, NY, USA). The radiographs were photographed, scanned and later used to localize the middle section of the defects. After radiography, the samples were first prepared with a sequential water substitution process which involved $48 \mathrm{hr}$ in $40 \%$ ethanol, $72 \mathrm{hr}$ in $70 \%$ ethanol (changed $24 \mathrm{hr}$ ), $72 \mathrm{hr}$ in $96 \%$ ethanol and finally $72 \mathrm{hr}$ in $100 \%$ ethanol. Samples were placed in xylene for $72 \mathrm{hr}$ for defatting of the recovered bone (changed every $24 \mathrm{hr}$ ). Next, infiltration was performed by placing the samples in methyl methacrylate (MMA) for $72 \mathrm{hr}$ (Fluka 64200) followed by three days in $100 \mathrm{ml} \mathrm{MMA}+2 \mathrm{~g}$ di-benzoylperoxid (Fluka 38581), at $4 \mathrm{C}^{\circ}$. Samples were embedded by placing them in $100 \mathrm{ml} \mathrm{MMA}+3$ g di-benzoylperoxid $+10 \mathrm{ml}$ plastoid $\mathrm{N}$ or dibuthylphtalat (Merck 800 19.25) and allowing polymerization to occur at $37 \mathrm{C}^{\circ}$ in a air tight water bath. $4.5 \mu \mathrm{m}$ sections were prepared from the middle of the defects and stained with Goldner Trichrome (Sheehan \& Hrapchak 1980). 


\section{Bone bridging}

In order to determine which percentage of the defect was already bridged by bone, the areas of the middle section with bone tissue were projected onto the x-axis, and the stretches where bone formation had occurred were summed up. Bone bridging is given in percentage of the defect width $(6 \mathrm{~mm})$.

\section{Histomorphometry}

Quantitative evaluation of bone regeneration was assessed by applying standard histomorphometric techniques. Measurements were carried out on a picture mosaic taken from the entire area of interest via a light microscope at a magnification of 160x, using a superimposed test grid of points and cycloid lines. The numbers of test points overlying the profiles of the different components (i.e. mineralized bone tissue, non-mineralized tissue and graft particles) were counted. Test points are defined and symbolized according to the standard nomenclature of the International Society for Stereology (Exner 1987) The graft to bone contact was calculated by the number of intersections between graft particles and the outlines of either mineralized bone or non-mineralized tissue.

\section{Statistical Analysis}

The primary unit of analysis was the animal. Mean values and standard deviations were calculated for the amount of bone formation, for bone bridging and for bone to bone substitute contact in the middle section within the original defect. The significance of differences was evaluated by the Friedman-test. Statistical analysis was performed by using a statistical software package (SPSS 12.0 for Windows). 


\section{Results}

\section{Descriptive histology}

During operation the different bone substitute materials could be applied easily especially after they had been wetted by a physiological saline solution (Figure 1). After operation no adverse reaction occurred. All the animals remained in good health.

The microscopic examination confirmed the lack of any adverse effects which could have been induced by the different bone substitutes. New bone formation mainly originated from the bony defect borders directed toward the centre of the defect. Complete bridging of the former defects with mineralized bone occurred in 1 of the samples treated with synthetic hydroxyapatite/silica oxide based granules (Fig. 2F). Solid cortical bone developed around the xenogenic hydroxyapatite particles (Fig. 2C,D) and the synthetic hydroxyapatite/silica oxide based particles (Fig. 2E,F). The solid appearance of the newly formed bone covering the bone substitutes was evident in both bone substitute groups at higher magnifications (Fig.2a-e).

\section{Histomorphometry}

Histomorphometric analyses of all defect sites have been performed on GoldnerTrichrome-stained middle sections. The histomorphometric results on newly formed bone tissue in the defect are $12.32 \pm 10.36 \%$ for the empty control, $17.47 \pm 6.42 \%$ for the DBBM group, and $21.20 \pm 5.32 \%$ for the group treated with synthetic $\mathrm{HA} / \mathrm{SiO}$ based granules (Fig. 3). No significant differences between the 3 treatment modalities were found. 


\section{Bony bridging}

Based on Goldner-Trichrome-stained middle sections newly formed bone bridged the defect to $38.33 \pm 37.55 \%$ in the empty control group, $54.33 \pm 22.12 \%$ in the DBBM granules group, and to $79.00 \pm 13.31 \%$ in the synthetic hydroxyapatite/silica oxide based granules group (Fig. 4). Bone bridging was not significantly different between these groups.

\section{Bone to bone substitute contact}

The results on bone to bone substitute contact were determined histomorphometrically by using randomly distributed cycloids distributed all over the middle section of the original defect. From all cycloids crossing the bone substitute border $46.38 \pm 18.98 \%$ entered immediately into bone tissue for the xenogenic and $59.86 \pm 14.92 \%$ for the synthetic hydroxyapatite/silica oxide based granules group. However, the elevated bone to bone substitute contact in the synthetic compared to the DBBM group was not significant (Fig. 5).

\section{Discussion}

For the here presented animal study about a synthetic hydroxyapatite/silica oxide based bone substitution material the calvarial defect model was chosen because of 1) the poor blood supply; 2) the lack of muscles and minuscule amount of bone marrow as potential source for stem cells; 3 ) and the bone quality which is characteristic of cranio-maxillofacial bones. All together this makes it a relevant and demanding model to test bone substitute materials (Schmitz \& Hollinger 1986) also for dental use (Jung et al. 2005). Since this model allows the creation of 4 non-critical size defects, 4 treatment modalities can be compared in a single animal, thus 
minimizing the number of animals needed. Due to the short healing period of 1 month, bone formation in the empty control is still progressing and the defect has not healed. Therefore these results are comparable with 1 month results in critical size defects where bone formation ceases after 24 weeks even if the defect has not healed (Honma et al. 2008).

The overall results suggest that in all categories evaluated the synthetic $\mathrm{HA} / \mathrm{SiO}$ based bone substitute material performed best, followed by the xenogenic hydroxyapatite, and the untreated defect. However, there were no significant differences between the two bone substitutes or the empty defect in bone formation (Fig. 3), bone bridging (Fig. 4) or bone to bone substitute contact (Fig 5). However, for all tested parameters, the average results for the HA/SiO group were always the highest.

The positive effect on bone formation in the HA/SiO group could at least partly derive from the presence of silica oxide in the initial phase, the exposure of natural hydroxyapatite nanoparticles, and the increased surface area achieved by omitting sintering during the production phase.

A positive effect of silica in the initial phase of bone regeneration has been found in other studies as well (Hing et al. 2006, Patel et al. 2005, Xu et al. 2004, Xu \& Khor 2007, Xu et al. 2008). This positive effect can also be claimed by the here tested $\mathrm{HA} / \mathrm{SiO}$ based material, since the nano-sized HA particles are embedded in a silica oxide gel phase (Gerike et al. 2006) and almost fully degrade over 8 months (Henkel et al. 2005, Henkel et al. 2006). Another type of hydroxyapatite based materials aim to use the positive effect of silica by silica oxide doping. For silica doped hydroxyapatite a positive effect on bone regeneration was claimed (Hing et al. 2006, Patel et al. 2005) although the bioavailability and effective silica concentrations might be too low for a biological response (Bohner 2009). Further analysis of the 
degradation and the release profile of ions from the $\mathrm{HA} / \mathrm{SiO}$ material as well as effects of released ions on bone forming cells are needed to fully understand the biological effect of the $\mathrm{HA} / \mathrm{SiO}$ material on bone regeneration.

Degradation of the silica oxide gel over time will lead to the exposure of the nanosized hydroxyapatite particles to the cells present in the bone defect. From other studies it is known that HA nanoparticles have a positive effect on bone formation (Liu et al. 2009) by promoting the osteogenic differentiation of mesenchymal stem cells. In the same study it was also shown that this positive effect is dependent on the concentration of HA nanoparticles and that an overload of particles has even an adverse effect on the osteogenic differentiation of mesenchymal stem cells (Liu et al. 2009). Therefore just the presence of HA nanoparticles in bone substitute materials is not sufficient to guarantee a positive biological effect.

Another interesting aspect of the $\mathrm{HA} / \mathrm{SiO}$ based material during degradation is the substitution of the $\mathrm{SiO}_{2}$ gel phase by a proteinaceous organic matrix consisting of alkaline phosphatase, collagen I and also growth factors like bone morphogenetic protein-2 (Götz et al. 2008). This substitution was found in human biopsies with healing times between 3.5 and 12 months. The study we performed reports on one month results, where this exchange was just beginning and might not affect the outcome of our experiment. Of more relevance in the short term might be the surface of the materials and the existence of micro and macropores. Most of the synthetic hydroxyapatite based materials are sintered during the production phase leading to specific surfaces of below $2 \mathrm{~m}^{2} / \mathrm{g}$, reduced micropores (Weibrich et al. 2000) and osteoconductivity (Henkel et al. 2006). The xenogenic and osteogenic DBBM exhibits a surface area of $79.7 \mathrm{~m}^{2} / \mathrm{g}$ (Weibrich et al. 2000) which is well in the range of synthetic HA/SiO with a surface area of $84.0 \mathrm{~m}^{2} / \mathrm{g}$ (Götz et al. 2008) and could be 
the reason why both materials show no significant difference in defect bone bridging, being the direct measure for osteoconductivity in this model.

\section{Conclusion}

There is evidence that the synthetic hydroxyapatite/silica oxide granules provide comparable results to a standard xenogenic bovine mineral in terms of bone formation and defect bridging in non critical size defects.

Acknowledgement: The authors would like to thank Alexandr Tchouboukov for the histologies and Artoss (Rostock Germany) to provide us with the materials and for taking over the cost for the animals.

\section{References}

Benke, D., Olah, A. \& Möhler, H. (2001) Protein-chemical analysis of bio-oss bone substitute and evidence on its carbonate content. Biomaterials 22: 1005-1012.

Bohner, M. (2009) Silicon-substituted calcium phosphates - a critical view. Biomaterials 30: 6403-6406.

Cancedda, R., Giannoni, P. \& Mastrogiacomo, M. (2007) A tissue engineering approach to bone repair in large animal models and in clinical practice. Biomaterials 28: 4240-4250.

Canullo, L. \& Dellavia, C. (2009) Sinus lift using a nanocrystalline hydroxyapatite silica gel in severely resorbed maxillae: Histological preliminary study. Clinical Implant Dentistry and Related Research 11: e7-e13.

Carlisle, E. M. (1970) Silicon: A possible factor in bone calcification. Science 167: 279-280.

Dietze, S., Bayerlein, T., Proff, P., Hoffmann, A. \& Gedrange, T. (2006) The ultrastructure and processing properties of straumann bone ceramic ${ }^{\circledR}$ and nanobone ${ }^{\circledR}$. Folia Morphol. 65: 63-65.

Esposito, M., Grusovin, M. G., Coulthard, P. \& Worthington, H. V. (2006) The efficacy of various bone augmentation procedures for dental implants: A cochrane systematic review of randomized controlled clinical trials The International Journal of Oral \& Maxillofacial Implants 21: 696-710.

Exner, H. E. (1987) A model stereological nomenclature. Acta Stereol 6 (suppl II): 179-184.

Gao, T., Aro, H. T., Ylänen, H. \& Vuorio, E. (2001 ) Silica-based bioactive glasses modulate expression of bone morphogenetic protein-2 mrna in saos-2 osteoblasts in vitro. Biomaterials 22: 1475-1483. 
Gerike, W., Bienengraber, V., Henkel, K. O., Bayerlein, T., Proff, P., Gedrange, T. \& Gerber, T. (2006) The manufacture of synthetic non-sintered and degradable bone grafting substitutes. Folia Morphol (Warsz) 65: 54-55.

Götz, W., Gerber, T., Michel, B., Lossdörfer, S., Henkel, K.-O. \& Heinemann, F. (2008) Immunohistochemical characterization of nanocrystalline hydroxyapatite silica gel (nanobone \& reg) osteogenesis: A study on biopsies from human jaws. Clinical Oral Implants Research 19: 1016-1026.

Gough, J. E., Jones, J. R. \& Hench, L. L. (2004) Nodule formation and mineralisation of human primary osteoblasts cultured on a porous bioactive glass scaffold. Biomaterials 25: 2039-2046.

Heinemann, F., Mundt, T., Biffar, R., Gedrange, T. \& Goetz, W. (2009) A 3-year clinical and radiographic study of implants placed simultaneously with maxillary sinus floor augmentations using a new nanocrystaline hydroxyapatite. J Physiol Pharmacol 60 Suppl 8: 91-97.

Henkel, K. O., Gerber, T., Dorfling, P., Gundlach, K. K. \& Bienengraber, V. (2005) Repair of bone defects by applying biomatrices with and without autologous osteoblasts. $J$ Craniomaxillofac Surg 33: 45-49.

Henkel, K. O., Gerber, T., Lenz, S., Gundlach, K. K. \& Bienengraber, V. (2006) Macroscopical, histological, and morphometric studies of porous bone-replacement materials in minipigs 8 months after implantation. Oral Surg Oral Med Oral Pathol Oral Radiol Endod 102: 606-613.

Hing, K. A., Revell, P. A., Smith, N. \& Buckland, T. (2006) Effect of silicon level on rate, quality and progression of bone healing within silicate-substituted porous hydroxyapatite scaffolds. Biomaterials 27: 5014-5026.

Honma, T., Itagaki, T., Nakamura, M., Kamakura, S., Takahashi, I., Echigo, S. \& Sasano, Y. (2008) Bone formation in rat calvaria ceases within a limited period regardless of completion of defect repair. Oral Diseases 14: 457-464.

Huang, D. M., Chung, T. H., Hung, Y., Lu, F., Wu, S. H., Mou, C. Y., Yao, M. \& Chen, Y. C. (2008) Internalization of mesoporous silica nanoparticles induces transient but not sufficient osteogenic signals in human mesenchymal stem cells. Toxicol Appl Pharmacol 231: 208215.

Jugdaohsingh, R., Tucker, K. L., Qiao, N., Cupples, L. A., Kiel, D. P. \& Powell, J. J. (2004) Dietary silicon intake is positively associated with bone mineral density in men and premenopausal women of the framingham offspring cohort. J Bone Miner Res 19: 297-307.

Jung, R. E., Schmoekel, H. G., Zwahlen, R., Kokovic, V., Hammerle, C. H. \& Weber, F. E. (2005) Platelet-rich plasma and fibrin as delivery systems for recombinant human bone morphogenetic protein-2. Clin Oral Implants Res 16: 676-682.

Liu, Y., Wang, G., Cai, Y., Ji, H., Zhou, G., Zhao, X., Tang, R. \& Zhang, M. (2009) in vitro effects of nanophase hydroxyapatite particles on proliferation and osteogenic differentiation of bone marrow-derived mesenchymal stem cells. Journal of Biomedical Materials Research Part A 90A: 1083-1091.

McAllister, B. S. \& Haghighat, K. (2007) Bone augmentation techniques. Journal of Periodontology 78: 377-396.

Patel, N., Brooks, R. A., Clarke, M. T., Lee, P. M., Rushton, N., Gibson, I. R., Best, S. M. \& Bonfield, W. (2005) In vivo assessment of hydroxyapatite and silicate-substituted hydroxyapatite granules using an ovine defect model. J Mater Sci Mater Med 16: 429-440.

Peetz, M. (1997) Characterization of xenogeneic bone material In: Boyne, P. J., ed. Osseous reconstruction of the maxilla and mandible, 87-93. Chicago: Quintessence.

Rico, H., Gallego-Lago, J. L., Hernández, E. R., Villa, L. F., Sanchez-Atrio, A., Seco, C. \& Gérvas, J. J. (2000) Effect of silicon supplement on osteopenia induced by ovariectomy in rats. Calcif Tissue Int 66: 53-55. 
Schmitz, J. P. \& Hollinger, J. O. (1986) The critical size defect as an experimental model for craniomandibulofacial nonunions. Clinical Orthopaedics and Related Research 205: 299308.

Schwarz, K. \& Milne, D. B. (1972) Growth-promoting effects of silicon in rats. Nature 239: 333-334.

Seaborn, C. D. \& Nielsen, F. H. (2002) Silicon deprivation decreases collagen formation in wounds and bone, and ornithine transaminase enzyme activity in liver. Biol Trace Elem Res 89: $247-258$.

Sheehan, D. C. \& Hrapchak, B. B. (1980) Bone In: Sheehan, D. C. \& Hrapchak, B. B., eds. Theory and practice of histotechnology. 2nd edition, 89-117. St. Louis, MO, USA: The CV Mosby Company.

Spector, M. (1994) Anorganic bovine bone and ceramic analogs of bone-mineral as implants to facilitate bone regeneration. Clinics in Plastic Surgery 21: 437-444.

Warnke, P. H., Springer, N.G., Wiltfang, J., Acil, Y., Eufinger, H., Wehmöller,M., Russo, P. H. J., Bolte, H., Sherry, E., Behrens, E. \& Terheyden, H. (2006) Repair of a human face by allotransplantation. Lancet 368: 181-183.

Weibrich, G., Trettin, R., Gnoth, S. H., Götz, H., Duschner, H. \& Wagner, W. (2000) Bestimmung der größe der spezifischen oberfläche von knochenersatzmaterialien mittels gasadsorption. Oral and Maxillofacial Surgery 4: 148-152.

Werner, J., Linner-Krcmar, B., Friess, W. \& Greil, P. (2002) Mechanical properties and in vitro cell compatibility of hydroxyapatite ceramics with graded pore structure. Biomaterials 23: 4285-4294.

Xu, H. H., Smith, D. T. \& Simon, C. G. (2004) Strong and bioactive composites containing nano-silica-fused whiskers for bone repair. Biomaterials 25: 4615-4626.

Xu, J. L. \& Khor, K. A. (2007) Chemical analysis of silica doped hydroxyapatite biomaterials consolidated by a spark plasma sintering method. J Inorg Biochem 101: 187-195.

Xu, S., Lin, K., Wang, Z., Chang, J., Wang, L., Lu, J. \& Ning, C. (2008) Reconstruction of calvarial defect of rabbits using porous calcium silicate bioactive ceramics. Biomaterials 29: 2588-2596.

Xynos, I. D., Edgar, A. J., Buttery, L. D., Hench, L. L. \& Polak, J. M. (2001) Gene-expression profiling of human osteoblasts following treatment with the ionic products of bioglass $45 \mathrm{~s} 5$ dissolution. J Biomed Mater Res A 55: 151-157.

\section{Figure legends}




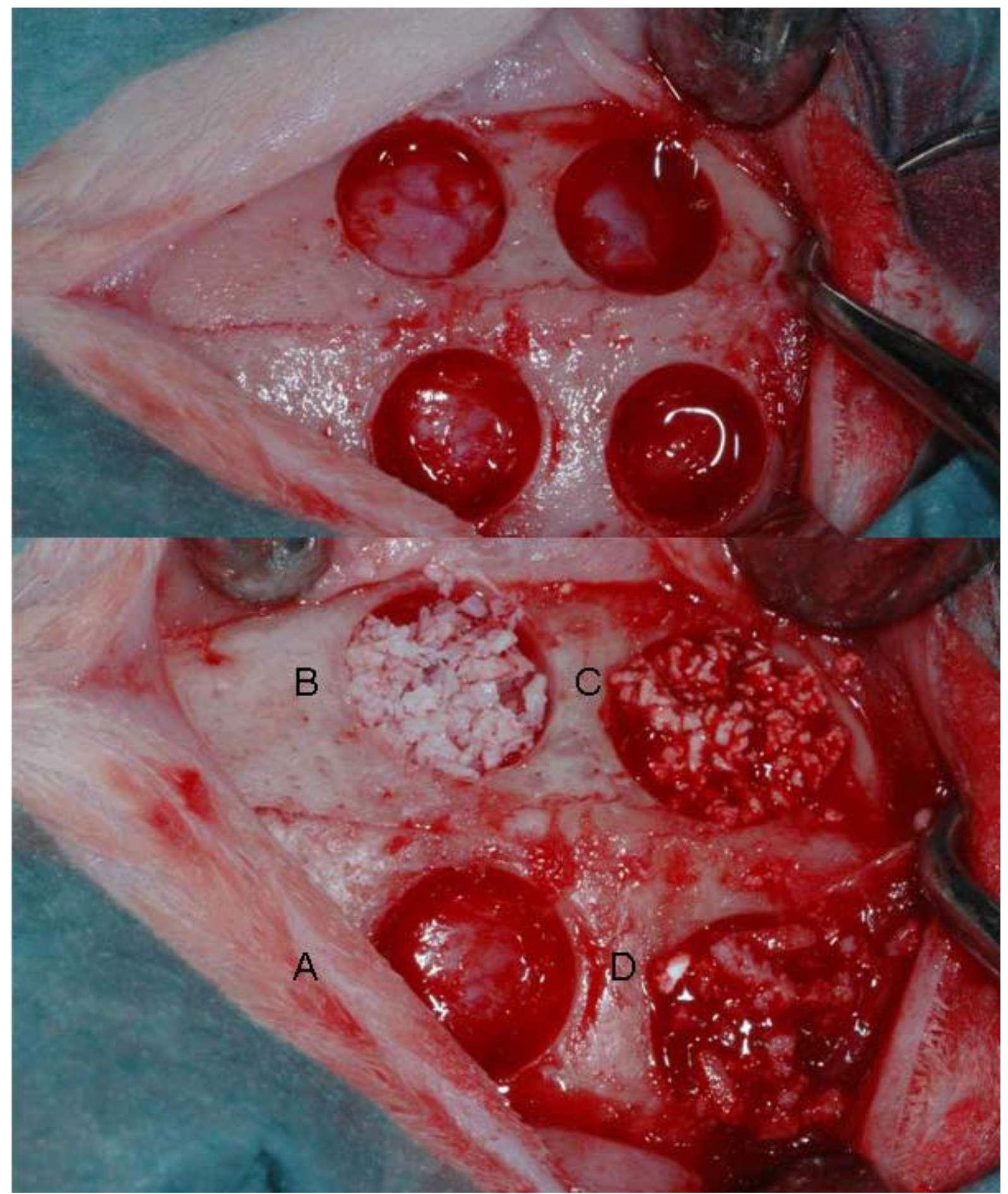

Fig. 1. Picture of the operative site showing one example for defects before and after application of bone substitute materials. A: empty, B: sintered bovine bone mineral (DBBM) $(0.25-1 \mathrm{~mm}), \mathrm{C}$ : Synthetic hydroxyapatite/silica oxide granules (HA/SiO) (0.25-1mm) D: Synthetic hydroxyapatite/silica oxide granules $(1-3 \mathrm{~mm})$ Please note that the size of the material (D) was much bigger than that of the other materials. Therefore these results are not reported here. 

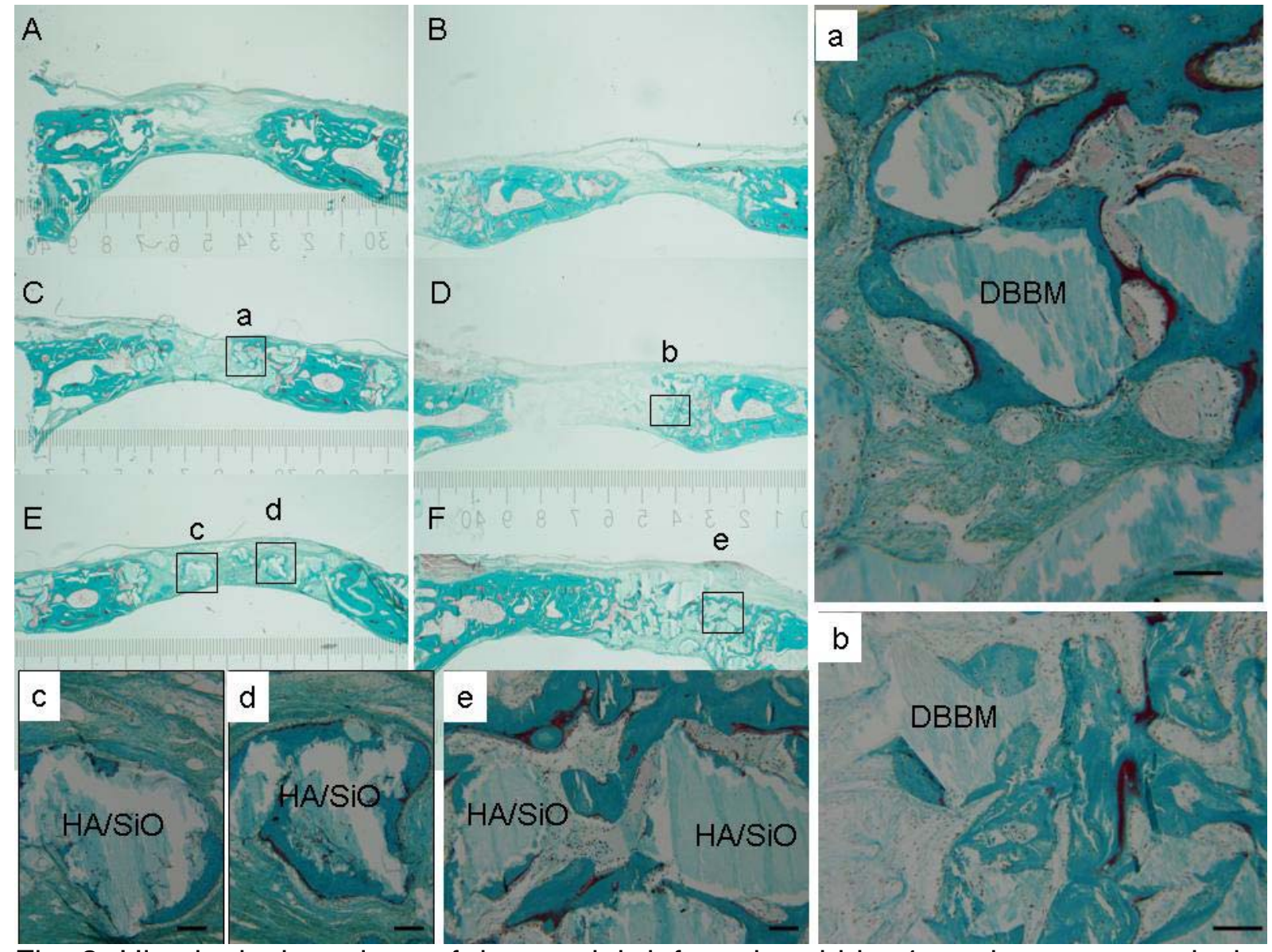

Fig. 2. Histological sections of the cranial defects in rabbits 4 weeks postoperatively: $(A, B)$ No filling (empty) as a negative control, (C,D) xenogenic bone mineral as a golden standard, (E,F) as test material. Scale in millimeters. Original magnifications were 100 fold. Histological sections of the cranial defects in higher magnifications: (a, b) sintered bovine bone mineral, (c, d, e) synthetic hydroxyapatite/silica oxide granules; scales provided are $100 \mu \mathrm{m}$. Original magnifications were 300 fold. The areas shown with higher magnification are indicated. 


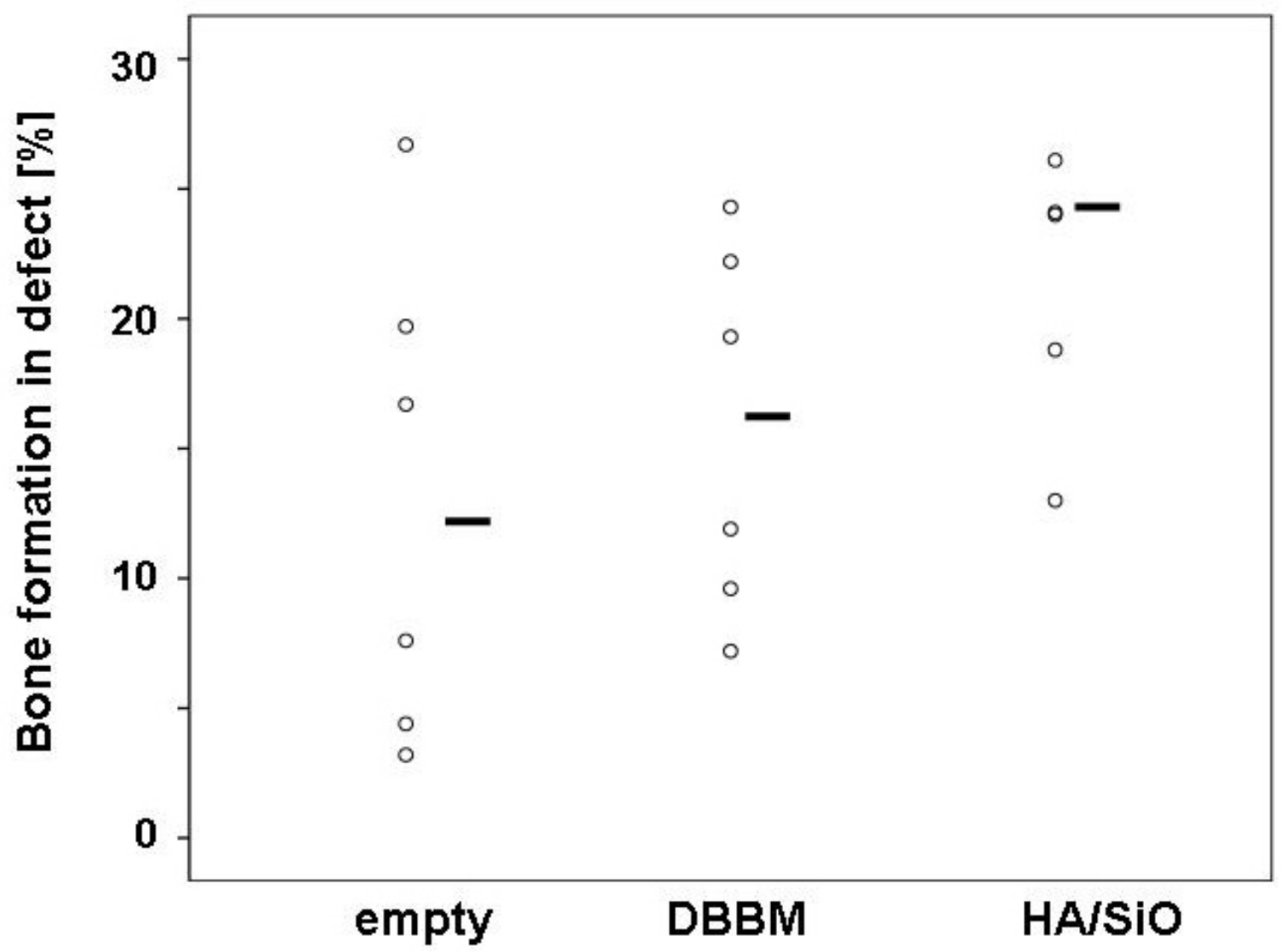

Fig. 3. Bone tissue within the defect. The lines to the right of the values indicate the median of the group. No significant differences between the groups were observed. 


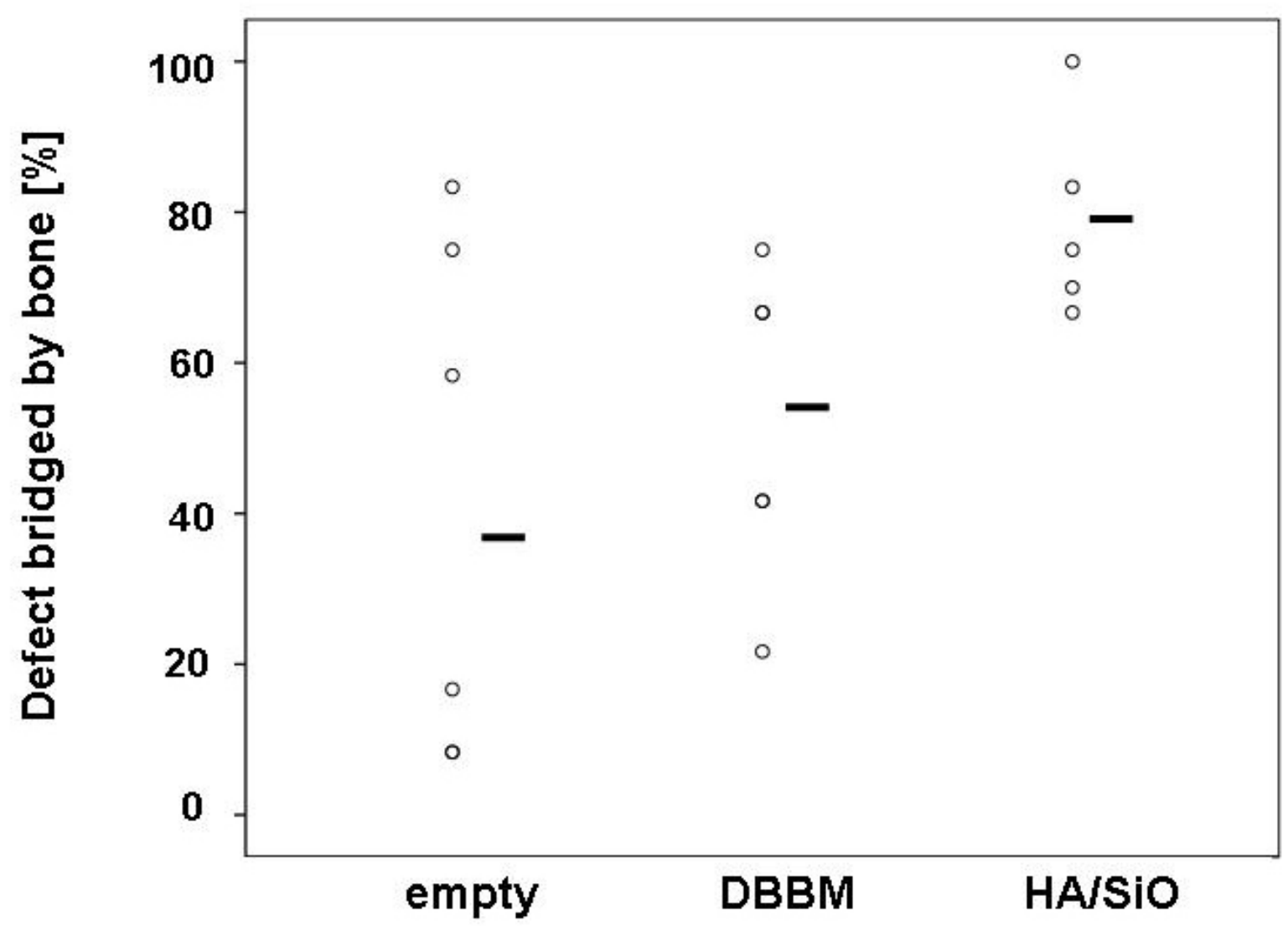

Fig. 4. Bony bridging is the percentage of the defect where new bone formation has occurred. The lines to the right of the values indicate the median of the group. No significant differences between the groups were observed. 


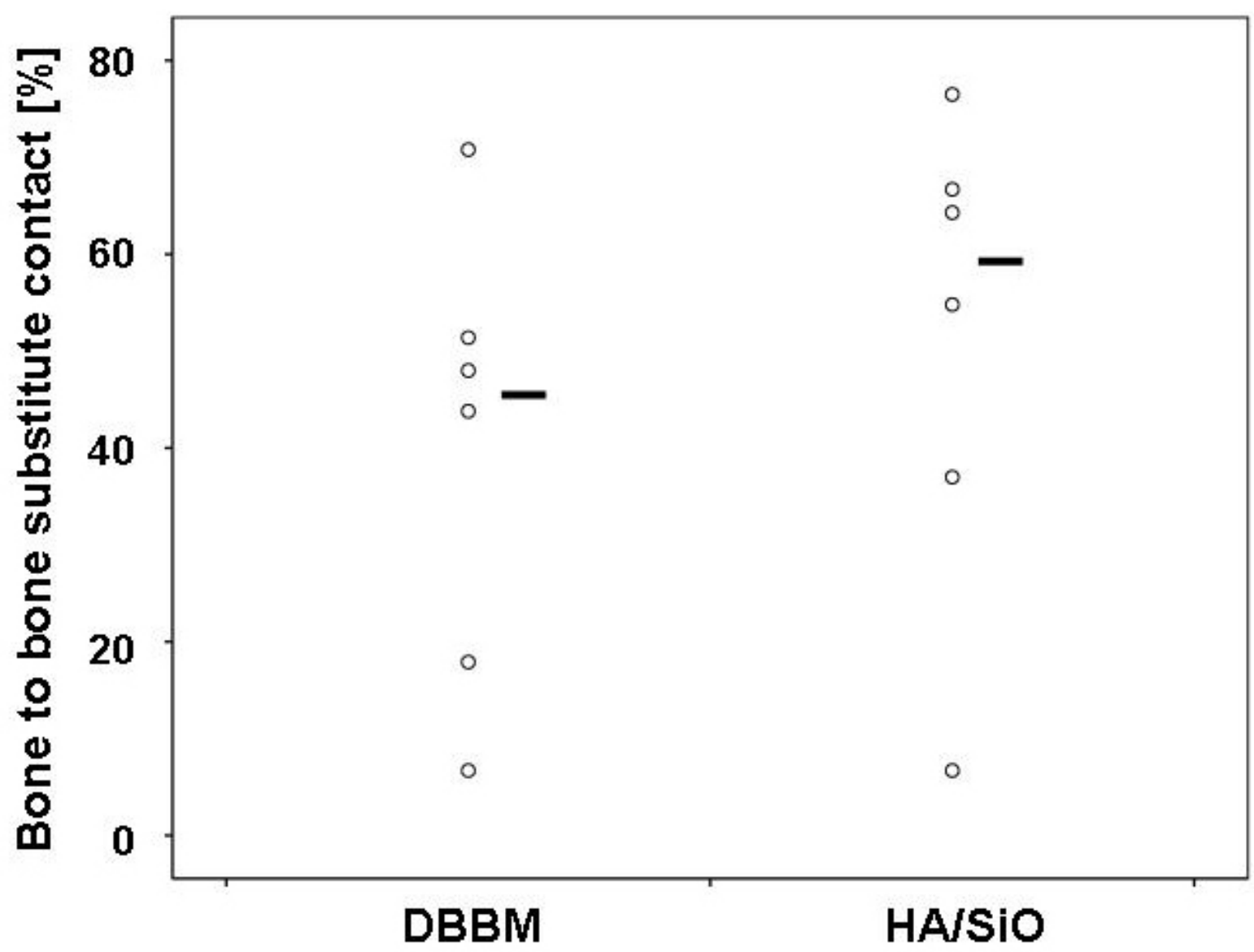

Fig. 5. Bone to bone substitute contact. The results of the histomorphometric analysis revealed no significant difference between the percentages of bone/bone substitute interface. The lines to the right of the values indicate the median of the group. 